\title{
Unilateral Liberalization versus Regional Integration: The Case of ECO Member Countries
}

\author{
Jahangir Khan Achakzai*
}

\begin{abstract}
Using an international dataset on bilateral trade for 137 countries in 2005, we estimate a gravity model to address the question of whether intra-Economic Cooperation Organization (ECO) trade is too low and whether the scale of trade at present is accounted for by regional integration or unilateral liberalization. The results of the gravity model confirm that intra-regional trade is lower than predicted by the gravity equation. The results also validates the theory that the present level of trade is attributed to regional agreements rather than unilateral liberalization, suggesting greater scope for regional cooperation among ECO member countries.
\end{abstract}

Keywords: Bilateral trade, economic cooperation organization, regionalism.

JEL Classification: N70, P45.

\section{Introduction}

Several theories of regionalism emerged in the 1990s as a response to the sudden upsurge of regionalism in the world in the second half of the 1980s and early 1990s. Some focused on the welfare effects of regionalism, while others tried to pin down the political economy rationale for such moves. In general, the success of the European Union (EU), the oldest regional scheme and the relation between the US and the EU, have spurred these theoretical developments. Studies of actual cases of integration, however, are far fewer.

In particular, the spread of regionalism among small countries and the possible motivation for these countries to enter into South-South regional integration agreements (RIAs) in the 1990s have received very little attention. Yet this kind of regionalism is booming once again and, as opposed to the frustrating experience of South-South regionalism in the 1970 s, seems to be succeeding.

*Associate Dean, Faculty of Management Sciences, Department of Economics, University of Balochistan, Quetta, Pakistan. 
What has pushed these countries to try the regional route once again? The purpose of this paper is to explore the motivation for recent regionalism among Economic Cooperation Organization (ECO) member countries. There has been a radical change in the foreign trade policy of ECO countries. Having restricted trade policies during the postwar period, the region turned toward more open regimes. What made regionalism in the ECO region suddenly so attractive was the evolution of regionalism in the North. There has been a significant revival of regionalism in that part of the world. Regional preferential trade agreements of different kinds have been established. As a result of such agreements, intra-regional trade has rapidly increased. The success of the EU and Association of Southeast Asian Nations (ASEAN) in promoting international trade and stimulating economic development has also encouraged other countries to form economic groups.

Seen in this perspective, Pakistan, Turkey, and Iran laid the foundations of Regional Cooperation for Development (RCD) in 1964. Under the RCD, member countries cooperated in the fields of trade, communications, banking, industry, political and cultural affairs, railways, and transportation. The organization was renamed the Economic Cooperation Organization or ECO in 1985. Seven new members, namely Afghanistan, Azerbaijan, Kazakhstan, Kyrgyzstan, Tajikistan, Turkmenistan, and Uzbekistan joined the regional bloc in May 1992.

Traditionally, almost all of the ten member countries of the ECO have been trading with each other for centuries. In order to institutionalize their traditional relations, member states took the initiative to establish the RCD in 1964 and ECO in 1985.

Pakistan is characterized by a policy of closer and growing relations with all countries in general and neighboring ones in particular. In light of the above mentioned policy, the country has been striving to strengthen trade ties with ECO countries. Unfortunately, their share in intraregional trade has remained negligible, despite the fact that the member countries of ECO are linked with each other geographically.

The available information presents a dismal picture of the current state of intraregional trade in the ECO region. Member countries still rely heavily on industrial economies for their exports and imports. Mutual trade in the region has become stagnant over time. The share of intraregional trade in the world trade of countries in the region remained more or less constant at around $6.0 \%$ in 2005 . Intraregional trade continues to remain a marginal part of the ECO. 
Keeping in view the background of ECO countries in terms of the status of their interrelated low share of trade, there is a need to ask why trade among ECO countries is so low and whether it can rise? The rest of the paper has been developed to respond to this question and to identify the magnitude of mutual trade. It can be said that there exists untapped/unexplored potential in the region, which needs to be harnessed through collaborative plans and actions to achieve the target of higher intraregional trade.

\section{Empirical Analysis}

\subsection{Theoretical Background of the Model}

The gravity model has been used widely used in the empirical literature to explain bilateral trade between countries. The first important attempt to provide a theoretical basis for gravity models was the work of Anderson (1979), which did so in the context of a model where goods were differentiated by country of origin and where consumers have preferences defined over all the differentiated products.

Deardorff (1998) shows that a gravity model can arise from a traditional factor-proportions explanation of trade and derived a gravity-type relationship from it. Anderson and Wincoop (2003) develop a model of monopolistic competition in differentiated products and Helpman, et al. (2004) developed a theoretical model of international trade in differentiated goods with firm heterogeneity. ${ }^{1}$

The important contribution of Anderson and Wincoop's (2003) paper has been to highlight that controlling for relative trade costs is crucial for a well-specified gravity model. Their theoretical results show that bilateral trade is determined by relative trade costs, that is, the propensity of country $i$ to import from country $j$ is determined by country $i$ s trade cost toward $j$ relative to its overall "resistance" to imports (weighted average trade costs) and to the average "resistance" facing exporters to country $j$, and not simply by the absolute trade costs between country $i$ and $j$.

In terms of the empirical gravity mode1, this implies that, after controlling for country size and bilateral distance, trade will be higher between country pairs that are far from the rest of the world than between country pairs that are close to the rest of the world.

\footnotetext{
${ }^{1}$ This model is built along the lines of Melitz (2003) where firms face fixed and variable costs of exporting. Firms vary by productivity, and only the more productive firms will find it profitable to export.
} 
McCallum (1995) concludes that whatever the reasons may be and whatever the future may hold, the fact that even the relatively innocuous Canada-US border continues to have a decisive effect on continental trade patterns suggests that national borders in general continue to matter.

Another recent study that applies the gravity model to RIAs is Franke1 (1996). He estimates a gravity model using a sample of 63 countries for various years between 1965 and 1992. In its basic form, Frankel's model includes dummies for adjacency, common language, and the traditional bloc dummies. His general conclusion is that the new wave of regionalism has resulted in a significant concentration of trade within different blocs all over the world. Even after holding constant for such natural determinants of bilateral trade such as size and distance, intraregional concentrations of trade continue to appear in various parts of the world. ${ }^{2}$

\subsection{Gravity Model}

Gravity models are econometric models of trade that have acquired their name from their similarity to Newton's theory of gravity. Newton's Law states that the force of gravity between two bodies is positively related to the mass of the attracting bodies and inversely related to the square of their distance. The gravity model of trade predicts that the volume of trade between any two countries will be positively related to the size of their economies (usually measured by gross domestic product [GDP]) and inversely related to the trade costs between them. ${ }^{3}$

The model in its most basic form says that trade between country $i$ and country $j$ is proportional to the product of GDP ${ }_{i}$ and $\mathrm{GDP}_{j}$ and inversely related to the distance between them. Other explanatory variables that are often added are other measures of size, namely, population and land areas and dummy variables like common borders, common language and common membership in regional trading arrangements.

\subsection{Estimation of the Reference Model}

The gravity equation used in the analysis is as follows:

$$
\begin{aligned}
\operatorname{Ln}\left(T_{i j}\right)= & \beta_{0}+\beta_{1} \operatorname{Ln}\left(G P_{i}\right)+\beta_{2} \operatorname{Ln}\left(G P_{j}\right)+\beta_{3} \operatorname{Ln}\left(\mathrm{PCI}_{\mathrm{i}}\right)+\beta_{4} \operatorname{Ln}\left(\mathrm{PCI}_{\mathrm{j}}\right) \\
& +\beta_{5} \operatorname{Ln}\left(\mathrm{DIST}_{\mathrm{ij}}\right)+\beta_{6}\left(\mathrm{ADJ}_{\mathrm{ij}}\right)+\beta_{7}\left(\mathrm{LANG}_{\mathrm{ij}}\right)+\beta_{8}(\mathrm{ECO})+\epsilon_{\mathrm{ij}}
\end{aligned}
$$

\footnotetext{
${ }^{2}$ Frankel (1996) p. 113.

${ }^{3}$ Roberta Piermartini and Robert Teh (2006).
} 
where $\mathrm{T}_{\mathrm{ij}}$ is the trade between country $i$ and country $j, \mathrm{GDP}_{\mathrm{i}}$ is the gross domestic product of country $i, \mathrm{GDP}_{j}$ is the gross domestic product of country $j, \mathrm{PCI}_{\mathrm{i}}$ is the per capita income of country $i, \mathrm{PCI}_{\mathrm{j}}$ is the per capita income of country $j$, DIST $\mathrm{i}_{\mathrm{ij}}$ is the distance between country $i$ and country $j$, and $\mathrm{ADJ}$ is the dummy variable for common borders. $\mathrm{ADJ}$ takes a value of 1 if two countries have a common border and 0 otherwise. $\mathrm{LANG}_{\mathrm{ij}}$ is the dummy variable for a common language which takes a value of 1 if two countries have a common language and zero otherwise. ECO is the dummy variable for countries belonging to the ECO bloc. It is 1 when both countries $i$ and $j$ are part of the agreement and 0 otherwise.

As trade is expected to increase with the size of the domestic economy (GDP), level of development (PCI), and common border (ADJ), and declines with distance (DIST), $\beta_{1}, \beta_{2}, \beta_{3}, \beta_{4}$ and $\beta_{6}$ should be positive, and $\beta_{5}$ negative.

We expect trade to be positively affected by economic size (GDP) and negatively related to distance (DIST). The coefficients on per capita income (PCI) could be positive or negative ${ }^{4}$. Since trade is expected to increase with the size of the domestic economy (GDP), the expected sign on $\beta_{1}$ is positive.

GDP per capita indicates the stage of development of the countries: ${ }^{5}$ countries with a higher income per capita may be expected to trade more than poorer countries. Distance, in turn, may be seen as a general proxy for the costs of trade behind which lie a variety of factors. Since a large part of these costs are made up by transport costs, various studies have gone through very detailed and complex measures of shipping distances. ${ }^{6}$

To the extent that neighboring countries can be expected to share many cultural traits, and that information from across the border is typically more readily available, a dummy for common borders or adjacency is normally also included in the gravity equation. Finally, and for the same reasons, having a common language should also be included.

Once all the above factors are considered, it is possible to assess whether or not a formal trade agreement is effective in concentrating trade among its members. To this end, dummy variables of bloc membership are

\footnotetext{
${ }^{4}$ The impact of per capita income on trade is not straightforward. On one hand, the Linder hypothesis says that intra-industry trade increases when countries have similar per capita incomes. On the other hand, the comparative advantage theory, which is premised on different factor endowments, predicts a decline in inter-industry trade when countries have a similar income.

${ }^{5}$ See Brada and Mendez (1985) and Frankel (1996).

${ }^{6}$ For a review of these, see Frankel (1996).
} 
added to the basic equation. If bilateral trade exceeds (or lies below) the 'normal' levels of trade (normality being defined as the sample's average bilateral trade flows) the bloc variables will be significantly different from zero.

The model was estimated using weighted least squares (WLS). The technique was used to take into account the presence of hetroskedasticity which arises when the variance of the error terms is not constant over all observations. In its presence, OLS estimators are unbiased and consistent but not efficient estimators of the true variance of the estimated parameters. Since one knows a priori that hetroskedasticity, if present, will be related to the size of the countries, the appropriate correction for it is the use of the WLS technique, using as weights a measure of the size of the countries. This is the procedure followed here, using as weights the logarithm of the exporter's GDP.

\subsection{Data}

The gravity equation was estimated for the year 2005. The export values for 137 countries were taken from the UN COMTRADE database. The data for GDP and PC GDP was obtained from the World Bank's (2005) World Development Indicators. The data related to the distance between capital cities and countries sharing borders and common languages was obtained from the French Centre for Exploratory Studies and International Information (Le CEPII, Centre d'Etudes Prospectives et d'Informations Internationales).

\subsection{The Dependent Variable}

There are two possibilities for measuring the size of a trade flow: at the point of export or at the point of import. Apart from the well-known differences in valuation-exports are valued at free-on-board prices, and imports usually at cost-insurance-freight prices-and apart from minor differences due to time-lags between the recording of exports by the exporting country and the recording of the same flow as an import by the importing country, these two measurements should produce the same results. This analysis uses mostly export data, most of which has been obtained from the UN COMTRADE database.

\subsection{Estimation Results}

The results of the model show that the three standard gravity variables (GDP, GDP per capita, and distance) are highly significant

statistically at a $5 \%$ level of significance. The same is the case with adjacency 
and language variables which are also significant statistically at a 5\% level of significance. All variables carry their expected signs.

Table-1: Gravity Model Estimation

Dependent Variable is Total Exports: Method of Estimation Weighted Least Squares, Weight is the $\log \left(G P_{i}\right)$

\begin{tabular}{lcc}
\hline Explanatory Variable & Coefficient & t-Statistic \\
\hline GDP $_{\mathrm{i}}$ & 1.095 & 102.13 \\
$\mathrm{GDP}_{\mathrm{j}}$ & 0.775 & 89.892 \\
$\mathrm{PCI}_{\mathrm{i}}$ & 0.076 & 5.67 \\
PCI $_{\mathrm{j}}$ & 0.076 & 6.225 \\
DIST $_{\mathrm{ij}}$ & -1.268 & -56.505 \\
Adjacency & 1.062 & 9.183 \\
Language & 0.915 & 18.89 \\
ECO & 1.132 & 4.34 \\
Constant & -27.934 & -82.808 \\
$\mathrm{R}^{2}$ & 0.627 & \\
Adjusted R & & \\
Std Error & 0.627 & \\
Heteroskedasticity & 2.1542 & - \\
DW & 520.928 & - \\
No. of Observations & 1.754 & \\
\hline
\end{tabular}

Table-1 presents the empirical results of the gravity model. The model's overall fit is good and compares favorably with other studies. As expected, trade increases with both domestic and foreign GDP and with per capita income, and falls with distance. Significant coefficients for GDP confirm that international trade is strongly affected by the trading partners' incomes. The estimated coefficient on the $\log$ of the exporting country GDP at 1.1 indicates that, when GDP increases by $1 \%$, trade increases by $1.1 \%$. In case of the importing country, the coefficient is 0.78 , indicating that, when GDP increases by $1 \%$, trade increases by $0.78 \%$. The GDP per capita coefficient is also significant statistically, indicating that richer countries do in fact trade more than poor ones. The results of GDP and per capita GDP are 
more or less the same when compared with the findings from other studies. For example, Clarete, Edmonds, and Seddon (2002), with a sample of 83 countries report exactly the same coefficients (1.1 for the GDP of the exporting country and 0.8 for the importing country's GDP). Franke1 (1996), with a sample of 63 countries finds a coefficient for GNP of 0.93 in the year 1992. His findings for per capita GNP during the same periods are reported to be 0.13 .

The coefficient on the $\log$ of distance is about -1.27 , indicating that when distance between two countries is 1\% higher, trade between them falls by $1.27 \%$. The value of the distance coefficient is large, reflecting that transportation and communication among most member countries are generally more costly and act as a significant barrier to trade.

In the case of adjacency, the results are slightly higher when compared with previous studies. The value of the dummy for adjacency is 1.062. This means that in 2005 , two bordering countries were trading $189 \%$ $[\exp (1.062)=2.89]$ more than two nonadjacent countries. The adjacency dummy being significant indicates that the extent of trade flows between countries is ceteris paribus higher if these countries share a border. As regards the dummy variable for common language, with a coefficient of 0.92 , it also has a heavy impact on trade.

Finally, if there were nothing to the notion of trade blocs, then the five basic variables in the gravity equation-size, per capita income, bilateral distance, common borders, and common languages-would account for most of the variation in bilateral trade flows, leaving little to attribute to a dummy variable indicating whether two countries are members of the same regional grouping. Variations in intraregional trade would be due solely to the proximity of countries and their rates of economic growth.

In our estimations the dummy variable is represented when both members of the country pair are among the ECO bloc. The estimated coefficient of ECO is significant statistically. The coefficient estimate is 1.1, indicating that in the year 2005, two members of ECO countries trade $210 \%$ more among themselves, after holding constant for GDP, proximity, and the other gravity variables.

\subsection{Pakistan Potential Trade with ECO Countries}

In order to predict Pakistan's potential trade with member states of the bloc, we compare the trade volumes estimated by the model with that 
of the actual trade volumes of the member countries by using the parameter estimates produced by the gravity equation.

The following equation is used to analyze the results of Pakistan's predicted exports.

$$
\begin{aligned}
\operatorname{Ln}\left(X_{i j}\right)= & -27.93+1.1 \operatorname{Ln}\left(G D P_{i}\right)+0.86 \operatorname{Ln}\left(G D P_{j}\right)+0.08 \operatorname{Ln}\left(P C I_{i}\right)+0.08 \\
& \operatorname{Ln}\left(P C I_{j}\right)-1.27 \operatorname{Ln}\left(D I S T_{i j}\right)+1.06\left(A D J_{i j}\right)+0.92\left(L A N G_{i j}\right)+1.13(E C O)
\end{aligned}
$$

The data for member countries GDP, PCI, and DIST etc., are used to estimate "normal" trade flows, which gives us an indication of the predicted trade volumes that prevail between member states of the regional bloc.

Table-2: Pakistan's Predicted Trade with the Reference Group (000, US\$)

\begin{tabular}{lccc}
\hline $\begin{array}{l}\text { Partner } \\
\text { Country }\end{array}$ & $\begin{array}{c}\text { Actual } \\
\text { Exports }\end{array}$ & $\begin{array}{c}\text { Predicted } \\
\text { Exports }\end{array}$ & $\begin{array}{c}\text { Actual: Predicted } \\
\text { Ratio }\end{array}$ \\
\hline Afghanistan & $222,316.7$ & $228,463.7$ & 0.973094 \\
Azerbaijan & $1,811.428$ & $8,813.905$ & 0.205519 \\
Iran, Islamic Rep & $41,775.36$ & $395,510.2$ & 0.105624 \\
Kazakhstan & $11,291.11$ & $91,980.18$ & 0.122756 \\
Kyrgyz Republic & $1,128.448$ & $12,934.89$ & 0.087241 \\
Tajikistan & 618.282 & $17,072.92$ & 0.036214 \\
Turkey & $110,097.9$ & $98,044.97$ & 1.122933 \\
Turkmenistan & $2,094.967$ & $15,134.69$ & 0.138421 \\
Uzbekistan & $7,570.992$ & $74,867.81$ & 0.101125 \\
\hline
\end{tabular}

As can be seen from Table-2, Pakistan's actual exports to ECO member countries were below the levels predicted by the model in each but one of the cases examined. The exception is found for Pakistan's exports to Turkey, where the actual level is $12 \%$ higher than the predicted value. At the other extreme, in the case of Tajikistan, exports are only $3 \%$ of the predicted value and there is a $97 \%$ potential for Pakistan's exports to the country. Afghanistan, being the second largest market for Pakistan's exports after Turkey and having a common border with Pakistan broadly matches the predicted value. The country received $97 \%$ of the exports predicted by the mode1. In case of Iran, exports are only $10 \%$ that of the predicted level, despite the fact that the country shares a border with Pakistan. Among the 
Central Asian countries, Azerbaijan is a major market for Pakistan's exports, and meets $20 \%$ of the predicted exports.

The results clearly indicate that there is considerable scope for an increase in Pakistan's exports to ECO member countries.

\subsection{ECO Bloc Dummy}

The results of the coefficient of the ECO bloc dummy are in line with the previous study by Clarete, Edmonds, and Seddon (2002). With a sample of 83 countries, the study "Asian regionalism and its effects on trade" reports a value of 1.7 for the ECO dummy coefficient. The value of the bloc dummy coefficient is lower in our study, one reason for which could be the large number (137) of countries included in our dataset. According to their findings, ECO countries tend to trade more intensely among themselves at the expense of trade with the rest of the world. Estimates showed that intra-bloc trade in the ECO region was higher at a statistically significant level in 1995 and 2000 than would be expected if the countries were not members of the ECO.

To add to the findings of Clarete, Edmonds, and Seddon (2002), our results were further analyzed to answer the question posed at the beginning of the paper, i.e. whether the existing level of trade is attributed to a regional agreement or whether it is due to the policy of unilateral liberalization among these countries. In the case of the ECO countries at different speeds and with different intensities, most of these countries went through significant changes in their policy orientations while simultaneously undertaking the formation or the renewal of different trade agreements. The explicit inclusion of the national policy variables that was attempted here (inclusion of the bloc openness dummy to the model in Table 3) and the comparison of the directions of trade after and before the signature of the agreements allows for a better understanding of the actual impact of these arrangements.

In the same way, to see each country's national policy effect separately, 10 country dummies were added to the model. The bloc effect can then be read as the extra impact on intraregional trade over the national policies effect. This technique allows for differences in national policies among member countries of the bloc. The results controlling for national policies are shown in Table-4. 


\subsection{Bloc Openness Dummy}

A comparison as to what happens to intra-bloc trade before and after any treaties have been signed involves both effects, and the estimated bloc coefficients therefore may be assigning to regional negotiations what in fact should be related to national policy. This would result in an overstatement of the bloc effect. In order to solve this problem a dummy variable for the general level of openness of the ECO bloc was added to our model.

This dummy takes the value of 1 when at least one country of the pair in question is a member of the group. The bloc effect can then be read as the extra impact on intraregional trade over the national policies effects. To a greater extent, this is similar to what Frankel (1996) does with his dummies for bloc openness. Table-2 shows the results controlling for national policy. The ECO openness dummy coefficient's value is negative and statistically significant. At the same time with the inclusion of the ECO openness dummy, the level of the coefficient of the ECO bloc dummy increases further. The above two results clearly indicate that a large part of intraregional trade growth in the ECO region should be attributed to regional agreements rather than to unilateral liberalization.

Table-3: Gravity Model Estimation with National Policy Dummy Dependent Variable is Total Exports: Method of Estimation Weighted Least Squares Weight is the Log (GDP)

\begin{tabular}{lccc}
\hline Variable & Expected Sign & Coefficient & t-Statistic \\
\hline $\mathrm{GDP}_{\mathrm{i}}$ & + & 1.098 & 102.531 \\
$\mathrm{GDP}_{\mathrm{j}}$ & + & 0.778 & 90.412 \\
$\mathrm{PCI}_{\mathrm{i}}$ & + & 0.062 & 4.631 \\
$\mathrm{PCIj}$ & + & 0.064 & 5.22 \\
$\mathrm{DIST}_{\mathrm{ij}}$ & - & -1.277 & -58.375 \\
Adjacency & + & 1.0681 & 9.334 \\
Language & + & 0.871 & 18.112 \\
ECO & & 1.32 & 4.983 \\
ECO Openness & & -0.267 & -4.57 \\
Constant & & -27.75 & -82.479 \\
Adjusted R & & 0.64 & \\
No. of Observations & & 16269 & \\
\hline
\end{tabular}




\subsection{Country Openness Dummy}

Similarly, to look at each country's national policy effect separately, 10 country dummies were added to the model. The dummies take the value of 1 whenever a particular country becomes part of a pair. The bloc effect can then be read as the extra impact on intraregional trade over the national policies effect. This method is different from the one above (the ECO openness dummy), which restricts all national policies to be the same, while the method followed here allows for differences among countries. Table-3 shows the results controlling for national policies.

Table-4: Gravity Model Estimation with National Policy Dummies Dependent Variable is Total Exports: Method of Estimation Weighted Least Squares Weight is the Log (GDP)

\begin{tabular}{lccc}
\hline Variable & Expected Sign & Coefficient & t-statistic \\
\hline GDP $_{i}$ & + & 1.097 & 101.75 \\
GDP $_{j}$ & + & 0.778 & 90.24 \\
PCI $_{i}$ & + & 0.062 & 4.62 \\
PCI $_{j}$ & + & 0.062 & 5.07 \\
DIST $_{\text {ij }}$ & - & -1.276 & -58.38 \\
Adjacency & + & 1.07 & 9.36 \\
Language & + & 0.861 & 17.85 \\
ECO & & 1.54 & 5.43 \\
AFG & & -1.0 & -5.68 \\
AZR & & 0.05 & 0.29 \\
IRN & & -0.78 & -5.37 \\
KAZ & & 0.06 & 0.36 \\
KYG & & -0.19 & -0.94 \\
PAK & & 0.09 & 0.67 \\
TAJ & & 0.05 & 0.23 \\
TKM & & -0.05 & -2.34 \\
TUR & & 0.11 & 0.82 \\
UZB & & -0.85 & -4.68 \\
Constant & & -27.72 & -81.75 \\
Adjusted R & & 0.64 & \\
No. of Observations & & 16,260 & \\
\hline
\end{tabular}


The results in Table 3 shows that, out of the ten countries, the coefficient on the openness dummy for four countries, namely, Afghanistan, Iran, Uzbekistan and Turkmenistan is negative and statistically significant, indicating that these countries are not open to world markets. Among these four countries Afghanistan seems to be the most restrictive country of the group, having a coefficient of -1.0 and a t-statistic of -5.68 . Iran follows Afghanistan with a dummy coefficient of -0.78 showing that the country is not open to world markets. The same is the case with Uzbekistan and Turkmenistan. The value of the coefficient on their dummies is reported as -0.85 and -0.05 , respectively. On the other hand, for the six remaining countries, the model reports values that are not statistically significant.

Moreover, with the inclusion of individual country dummies in the mode1, the results suggests that intraregional cooperation in the ECO is stronger than originally estimated (Table 1), where the ECO bloc dummy increases from 1.13 to 1.54 . It indicates that the growth in trade among these countries is not at the cost of intraregional trade in the ECO region. It further explains the fact that the rise in trade in these countries is not attributed to unilateral liberalization but rather to regional agreements among the countries.

\section{Conclusions}

The debate on the causes of regionalism and its implications for the world trading system is a long and unsettled one. Theoretical explanations abound, but actual studies are far fewer. The contribution of this paper is its empirical approach to regionalism in the ECO region, a region with a long story of regional integration agreements, many of which failed and some of which seem to be succeeding-success being defined as the arrangement's ability to promote intraregional trade among its member countries.

The political economy of the ECO member countries is changing radically. Export-oriented groups have started to dominate the political scene of ECO countries. The duty free entrance of Mediterranean products in Europe and of Mexican products in the US market has jeopardized the competitive position of the countries' exports in these markets. The revival of regionalism in this part of the world is because of the need of these export-oriented groups to at least maintain the status quo in their main export markets. Too small to negotiate trade concessions with the EU or the US, ECO member countries are left with the option of regionalism. With export-oriented groups counterbalancing protectionist pressure 
groups, this time there is strong hope for the success of regionalism in the ECO region.

Although generalizations cannot easily be drawn from this empirical approach, the results obtained in this paper give some interesting insights into the expected reactions of small countries to changes in larger countries. The results obtained from the gravity model predict that the ECO bloc has the potential to boost intraregional trade among its member countries. To what extent has the sub-regional agreement in the ECO region succeeded in concentrating trade among their members? No worthwhile empirical studies exist except the study by Clarete, Edmonds, and Seddon (2002). Their findings are in line with the result of the present study. Their estimates show that intra-bloc trade in the ECO region was higher at a statistically significant level than would be expected if the countries were not members of the ECO.

The findings of the paper show that trade between ECO member countries are is far lower than its inherent potential. The results were further analyzed to address the question as to whether the existing trade could be attributed to regional agreement or whether it was on account of unilateral liberalization among these countries. In the case of the ECO countries, most of these countries went through significant changes in their policies while simultaneously undertaking the formation or the renewal of different trade agreements. The explicit inclusion of the national policy variables that was attempted here, and the comparison of the directions of trade after and before the signature of trade agreements allows for a better understanding of the actual impact of these arrangements. In this light, the effect of the ECO bloc looks impressive.

What these results show is that the main determinant in the change of ECO countries' trade flows in the past has been the process of regionalism and not unilateral liberalization. The main achievement of this economic integration seems to have been to redress a pattern of trade in the case of most of the member countries that was heavily distorted by protectionist policies adopted by countries in the past. It strengthens the case for further trade liberalization in the ECO region, possibly in the context of greater regional integration. Greater regional integration, in a way that is compatible with multilateral liberalization, could contribute to growth not only by increasing trade and allowing regional producers to benefit from economies of scale, but also by encouraging foreign direct investment and the deepening of capital markets. 
Where is it heading to? The main winner of the new ECO trade orientation would be intra-ECO trade. Reduced in the past by protectionist trade policies throughout the region, intra-ECO trade will increase as these countries turn toward more open trade regimes. In this regard, the initiatives in regional integration is a step towards that end: in 2003, the ECO member countries signed the ECO Trade Agreement (ECOTA) under which tariffs will be reduced for participating members to a maximum of $15 \%$ as the highest tariff slab in eight years. 


\section{References}

Anderson, J.E. (1979). Regional Integration and International Trade in the context of EU Eastward Enlargement: A Theoretical Foundation for the Gravity Equation. American Economic Review, 69 (1), 106-116.

Anderson, J., and E. van Wincoop. (2003). Gravity with Gravitas: A Solution to a Border Puzzle. American Economic Review, 93(1), 170-192.

Bhagwati, J., and Panagariya, A. (1996). Preferential Trade Areas and Multilateralism: Strangers, Friends or Foes? In Bhagwati, J. and Panagariya, A. (eds) The Economics of Preferential Trade Agreements. AEI Press: Washington.

Brada, J.C., and Mendez, J.A. (1985). Economic Integration among Developed, Developing and Central Planned Economies: A Comparative Analysis. Review of Economics and Statistics, 67, 549556.

Brown, D.K., Deardoff, A.V. and Stern, R.M. (2003). Multilateral, Regional and Bilateral Trade Policy Options for US and Japan. The World Economy, 26(6), 803-828.

Clarete, E., and Seddon (2002). Asian Regionalism and its Effects on Trade in the 1980s and 1990s'. Asian Development Bank.

Deardoff, A. (1995). Determinants of Bilateral Trade: Does Gravity Work in a Classical World? NBER Working Paper 5377.

De Melo, J. and Panagariya, A. (eds) (1996). New Dimensions in Regional Integration. London Economic Cooperation Organization (ECO) Secretariat database, (2003). Cambridge University Press.

Fernandez, R. (1997). Returns to Regionalism: An Evaluation of Non Traditional Gains from Regional Trade Agreements. The World Bank, Policy Research Working Paper 1816.

Franke1, J.A. (1996). Regional Trading Blocs in the World Economic System. Institute for International Economics, Washington.

French Centre for Exploratory Studies and International Information (Le CEPII) (2009). Centre d'Etudes Prospectives et d'Informations Internationales). Georges Pitard - 75740 Paris Cedex 15. 
Institute of Regional Studies (1995). Pakistan and Regional Economic Cooperation in SAARC - ECO. Islamabad: Pakistan.

Franke1, J. (1964). International Relations. New York: Oxford University Press.

Kamal A.R. (1995). Significance of SARRC and ECO, Pakistan Institute of Regional Studies. Islamabad: Pakistan.

Khan, A.H. (1995). Intraregional Trade in South Asia Problems and Prospects' Institute of Regional Studies Islamabad. Pakistan.

Krugman, P. (1992). Regionalism vs. Multilateralism: Analytical Notes. In de Melo and Panagariya (eds.), New Dimensions in Regional Integration. Center for Economic Policy Research. New York: Cambridge University Press.

McCallum (1995). National Borders Matter: Canada-U.S. Regional Trade Patterns. American Economic Review, 85(3), 615-623.

Maqbool, A.B. (1992). ECO Challenge and Opportunities in the 1990's. Strategic Studies. 2, 16.

Maqbool, A.B. (1995). Pakistan and ECO. Regional Studies, 103.

Mukherjee, R. (1997). Regionalism in South Asia: Theory \& Praxis. Pacific Affairs, 70(2), 235-251.

Naseem, Z. (1992). ECO Challenges and Opportunities in the 1990's'. Strategic Studies, 2, 31.

Rodrik, D. (1992). The Rush to Free Trade in the Developing World: Why So Late, Why Now? Will it Last? Working Paper No. 3947, N.B.E.R., Cambridge.

Shahi, A. (1992). The ECO, Prospects and Problems. Khalij Times.

Soloaga, I. and Winter, A. (1999). Regionalism in the Nineties: What Effect on Trade? The World Bank, Policy Research Working Paper 2156.

UN Commodity Trade Statistics Database (COMTRADE), United Nations Statistics Division. 
Viner, J. (1950). The Customs Union Issue. New York: Carnegie Endowment for International Peace.

World Bank (2005). World Development Indicators, Washington, D.C.

World Trade Organization (1995). Regionalism and the World Trading System. W'TO: Geneva. 